\title{
The induction of behavioural sensitization is associated with cocaine-induced structural plasticity in the core (but not shell) of the nucleus accumbens
}

\author{
Yilin Li, Martin J. Acerbo and Terry E. Robinson \\ Department of Psychology (Biopsychology) and Neuroscience Program, The University of Michigan, East Hall, 525 East University, \\ Ann Arbor, MI 48109-1109, USA
}

Keywords: cocaine, dendrites, dendritic spines, frontal cortex, rat, synaptic plasticity

\begin{abstract}
Repeated exposure to cocaine increases the density of dendritic spines on medium spiny neurons in the nucleus accumbens (Acb) and pyramidal cells in the medial prefrontal cortex (mPFC). To determine if this is associated with the development of psychomotor sensitization, rats were given daily i.p. injections of $15 \mathrm{mg} / \mathrm{kg}$ of cocaine (or saline) for 8 days, either in their home cage (which failed to induce significant psychomotor sensitization) or in a distinct and relatively novel test cage (which induced robust psychomotor sensitization). Their brains were obtained 2 weeks after the last injection and processed for Golgi-Cox staining. In the Acb core $(\mathrm{AcbC})$ cocaine treatment increased spine density only in the group that developed psychomotor sensitization (i.e. in the Novel but not Home group), and there was a significant positive correlation between the degree of psychomotor sensitization and spine density. In the Acb shell (AcbS) cocaine increased spine density to the same extent in both groups; i.e. independent of psychomotor sensitization. In the mPFC cocaine increased spine density in both groups, but to a significantly greater extent in the Novel group. Furthermore, when rats were treated at Home with a higher dose of cocaine $(30 \mathrm{mg} / \mathrm{kg})$, cocaine now induced psychomotor sensitization in this context, and also increased spine density in the AcbC. Thus, the context in which cocaine is experienced influences its ability to reorganize patterns of synaptic connectivity in the Acb and mPFC, and the induction of psychomotor sensitization is associated with structural plasticity in the AcbC and mPFC, but not the AcbS.
\end{abstract}

\section{Introduction}

Repeated intermittent exposure to drugs of abuse can render animals hypersensitive (sensitized) to some drug effects, and to drug-related stimuli, even long after the discontinuation of drug treatment (Segal \& Mandell, 1974; Robinson \& Becker, 1986). Most studies have focused on the psychomotor activating effects of drugs (psychomotor sensitization), but repeated treatment with psychomotor stimulant drugs also facilitates Pavlovian conditioned motivational processes (Harmer \& Phillips, 1998, 1999; Taylor \& Horger, 1999; Wyvell \& Berridge, 2001), the later acquisition of drug self-administration (Piazza et al., 1989; Horger et al., 1990; Pierre \& Vezina, 1998), the acquisition of a preference for places associated with drug administration (Lett, 1989) and the 'breakpoint' achieved on a progressive ratio schedule (Mendrek et al., 1998; Lorrain et al., 2000). On the basis of these studies (for a review, see Vezina, 2004) it has been hypothesized that drug-induced adaptations in the brain associated with the induction of behavioural sensitization contribute to the development of addiction (Robinson \& Berridge, 1993, 2003).

There has therefore been considerable interest in the neurobiology of sensitization, and many neurobiological correlates of sensitization have been reported, especially in the nucleus accumbens (Acb) and associated circuitry (Pierce \& Kalivas, 1997; Vanderschuren \&

Correspondence: Dr T. E. Robinson, as above.

E-mail: ter@umich.edu

Received 27 October 2003, revised 18 June 2004, accepted 13 July 2004
Kalivas, 2000). In most previous studies designed to identify neurobiological correlates of sensitization a drug is given repeatedly and then later the brain is examined to determine if drug treatment produced any persistent change in the neurobiological measure of interest. However, in such studies it is not possible to tell if any given drug-induced neuroadaptation is related specifically to the development of behavioural sensitization, or whether it would occur even if drug treatments failed to induce sensitization (i.e. as a function of mere drug history). We have developed a procedure to do this. There are doses of amphetamine or cocaine that are relatively ineffective in producing psychomotor sensitization if given in an animal's home cage, but induce robust psychomotor sensitization if given in a distinct and relatively novel test cage (Badiani et al., 1995; Crombag et al., 1996; Browman et al., 1998a). Thus, in this situation two randomly assigned groups (Home vs. Novel) have the same drug history, but only one group develops robust psychomotor sensitization. If any given drug-induced change in the brain is associated with the development of sensitization it should be present in the Novel, but not the Home group; unless dose is increased so that now drug treatments induce sensitization even at Home (Browman et al., 1998a,b).

The purpose of the present experiment was to manipulate the induction of psychomotor sensitization by varying environmental context and dose to determine whether one neurobiological consequence of exposure to cocaine, its ability to alter synaptic organization in the Acb and the medial frontal cortex (mPFC) (Robinson \& Kolb, 1999; Robinson et al., 2001) is related to its ability to induce 
psychomotor sensitization, or whether cocaine induces this form of structural plasticity independent of its ability to induce sensitization (i.e. merely as a function of drug history).

\section{Methods}

Male Sprague-Dawley rats (200-225 g) obtained initially from Harlan (Indianapolis, IN, USA) were housed individually in an animal colony room (14-h light : 10 -h dark cycle) in clear plastic hanging cages $(24 \times 21.6 \times 20.3 \mathrm{~cm})$ with shredded paper bedding for 7 days prior to any experimental manipulation. Food and water were available at all times. All experimental procedures were approved by the University of Michigan Committee on the Use and Care of Animals.

\section{Experiment 1}

Procedures

After 7 days, rats were assigned randomly to one of two groups. Rats in one group (Home) were transferred from the animal colony to a room where they were housed in transparent plastic rectangular cages $(41 \times 25.4 \times 20.3 \mathrm{~cm})$ that contained a clear plastic insert in the centre of the cage $(23 \times 6.3 \times 20.3 \mathrm{~cm})$. This insert formed a corridor around the perimeter of the cage where the animals could walk. Ground corncob bedding was located on the floor. These cages were located inside a frame that contained photocell emitters and detectors that could be used to record the movement of an animal from one end of the cage to the other (crossovers). The animals remained in these cages for the duration of the experiment. Animals in the other group (Novel) were left in the animal colony room.

After seven additional days of habituation to these conditions, during which time all animals were periodically handled, rats in the Novel group were transferred from their home cages to photocellequipped test cages that were identical to the ones in which the Home group lived. After $60 \mathrm{~min}$ in these test cages, the animals were given an intraperitoneal (i.p.) injection of either $1 \mathrm{~mL} / \mathrm{kg}$ of $0.9 \%$ saline (Novel/Saline, $n=8$ ) or $15 \mathrm{mg} / \mathrm{kg}$ of cocaine $\mathrm{HCl}$ (Novel/Cocaine, $n=12$; cocaine from NIDA) and behaviour recorded for an additional 90 min before the animals were returned to their home cages in the animal colony room. This procedure was repeated each day for a total of eight consecutive days. At the same time as the animals in the Novel group received an injection, animals in the Home group were also given an i.p. injection of either saline (Home/Saline, $n=8$ ) or $15 \mathrm{mg} / \mathrm{kg}$ of cocaine (Home/Cocaine, $n=12$ ), and were then placed immediately back into their home cage and behaviour monitored. After the last injection of saline or cocaine, the animals were left undisturbed for 2 weeks before their brains were obtained.

\section{Experiment 2}

\section{Procedures}

The procedures for this experiment were exactly the same as for experiment 1, except for the following modifications: (i) there was only a Home group, and half of these animals received cocaine ( $n=12)$ and half saline $(n=11)$; (ii) on the first test day, cocainetreated animals received injections of escalating doses of cocaine (7.5, 15 and $30 \mathrm{mg} / \mathrm{kg}$ ), with $1 \mathrm{~h}$ between each injection (and saline-treated animals received three injections of saline). On each of the next seven daily test sessions, the animals received a single injection of $30 \mathrm{mg} / \mathrm{kg}$ of cocaine (or saline). On the last test day, cocaine-treated animals again received escalating doses of cocaine $(7.5,15$ and
$30 \mathrm{mg} / \mathrm{kg}$ ), with $1 \mathrm{~h}$ between each injection (and saline-treated animals received three injections of saline). This procedure allows the construction of a dose-response function on the first and last day of treatment. Sensitization is indicated by a shift to the left in the doseresponse function. As in experiment 1, the animals were left undisturbed for 2 weeks after the last test session before their brains were obtained.

Note that in these experiments we did not test independent groups of animals after 2 weeks of withdrawal to ensure that sensitization persisted in the Novel group and did not appear in a delayed fashion in the Home group (e.g. there were no saline-treated groups that received a drug challenge). This was because we have reported the effects of a withdrawal period in seven different published papers using these procedures, many involving multiple behavioural experiments. In all cases the Home/Novel difference described here was also evident after a period of withdrawal (Badiani et al., 1995; Crombag et al., 1996; Browman et al., 1998a). Therefore, we were confident this would be the case here as well, and did not run independent groups to limit the number of animals used.

\section{Anatomical procedures}

After the 2-week drug-free period, the animals were deeply anaesthetized with an overdose of sodium pentobarbital and perfused through the heart with $0.9 \%$ saline. The brains were removed and placed in vials containing Golgi-Cox solution (Gibb \& Kolb, 1998) and after 14 days transferred to vials containing a $30 \%$ sucrose solution. After at least 3 days in the sucrose solution, the brains were cut into $200-\mu \mathrm{m}$ thick coronal sections using a vibrating microtome, and stained using procedures described by Gibb \& Kolb (1998).

We focused our analyses on medium spiny neurons in the shell of the nucleus accumbens (AcbS) and the core of the nucleus accumbens (AcbC), because (i) these regions are embedded in very different circuitry (Groenewegen et al., 1991; Zahm, 2000) (ii) they play different roles in the behaviours and psychological processes that undergo sensitization (Cardinal et al., 2002) and (iii) repeated drug treatments have different effects on the AcbC and AcbS (Cadoni \& Di Chiara, 2000; Cadoni et al., 2000). In experiment 1, we analysed pyramidal cells in the mPFC as well, because we previously found sensitization-related structural adaptations in these cells (Robinson \& Kolb, 1997, 1999).

Note that experiments 1 and 2 were conducted $\approx 1$ year apart and the tissue was analysed using different scopes and procedures (e.g. NEUROLUCIDA ${ }^{\circledR}$ software was used in experiment 1 with a final magnification of $4000 \times$ and in experiment 2 manual camera lucida procedures with a final magnification of $2000 \times$ were used), although the same experimenter (Li) conducted the anatomical analysis in both experiments.

In experiment 1, a Leica model DMRE microscope equipped with an Ludl XYZ motorized stage and NEUROLUCIDA ${ }^{\circledR}$ software (http://www.microbrightfield.com) was used to identify cells, trace dendritic segments and count dendritic spines. Cells from each brain region were first identified at low power $(100-125 \times)$. To be included in the analyses, the dendritic tree of a cell had to be wellstained and visible, and not obscured by blood vessels, glia or other cells. Given the relatively small number of cells that were wellstained and met these criteria, nearly all the available cells in a given section were included in the analyses. In addition, cells were sampled over the entire extent of the AcbC and AcbS, so the sample does reflect any specific subregion within these structures. Most importantly, the person who selected and analysed cells (Li) 
was blind to the experimental condition, so the same criteria were applied to all groups. Thus, any variation in spine density due to variation in the location of cells contributed to the experimental error effect.

For medium spiny neurons, one third-order (or greater) terminal tip was identified, and the total number of visible spines along the length of the dendritic segment (at least $20-\mu \mathrm{m}$ long) were counted. This was performed with a total magnification on the scope of $1600 \times$, and with additional magnification from the video signal the final magnification on the video screen was $\approx 4000 \times$. We focused on third order or greater terminal dendritic segments because we found previously that amphetamine treatment increases spine density on distal, but not proximal, dendrites of medium spiny neurons (Li et al., 2003). For pyramidal cells, spines were counted on one terminal tip per neuron (third order or greater) from both the apical and basilar dendritic tree. The NEUROLUCIDA ${ }^{\circledR}$ program calculated the total length of the dendritic segment and the number of spines $/ 10 \mu \mathrm{m}$ of dendrite. These measures were obtained from at least five cells in each hemisphere of each animal, and statistical analyses were conducted after averaging across cells within a hemisphere (i.e. hemisphere was the unit of analysis). In experiment 1 , the data represent a total sample of 385 cells in the AcbC, 391 cells in the AcbS, 314 (for apical dendrites) and 346 (for basilar dendrites) cells in the mPFC. Data were not available for every hemisphere in every brain region because of tissue damage or poor staining, and therefore, the $n$ for the saline-treated groups varies from 14-16, and for the cocaine-treated groups from 20-24. In experiment 2, cell selection and quantification was the same as in experiment 1 , except conventional camera lucida procedures were used, with a total magnification of $2000 \times$.

\section{Results}

\section{Experiment 1}

\section{Behaviour}

Figure 1 shows the number of cage crossovers, an index of locomotor activity, during the first and last (8th) test session in animals treated with cocaine or saline. A two-way ANOVA comparing the two groups that received cocaine resulted in a significant main effect of group $(F=11.99, P<0.002)$, of test session $(F=27.17, P<0.0001)$, and a significant group $\times$ test session interaction $(F=14.92, P<0.002)$. Planned between-subjects comparisons indicated that there was no difference between the Home/Cocaine and Novel/Cocaine groups on the first day of testing $(t=0.53, P=0.6)$, but there was on the last day of testing ( $t=3.86, P=0.0009)$. Planned within-subjects paired $t$-tests showed that there was a significant increase in crossovers between day 1 and day 8 of testing in the Novel/Cocaine group $(t=5.28, P=0.0003)$, but not in the Home/Cocaine group $(t=1.08, P=0.3)$. Thus, only the Novel/Cocaine group showed behavioural sensitization, and the Novel/Cocaine group changed over time to a greater extent than the Home/Cocaine group (as indicated by the interaction effect).

\section{Anatomy}

Nucleus accumbens. Figure 2 shows the effect of cocaine treatment on the density of dendritic spines on medium spiny neurons in the AcbC and AcbS. For the AcbC, a two-way ANOVA resulted in a significant group by drug interaction $(F=6.1, P=0.016)$. Post-hoc Fisher's tests indicated that cocaine significantly increased spine density in the Novel group $(P<0.0001)$, but not in the Home group $(P=0.78)$. For the AcbS a two-way ANOvA resulted in no significant

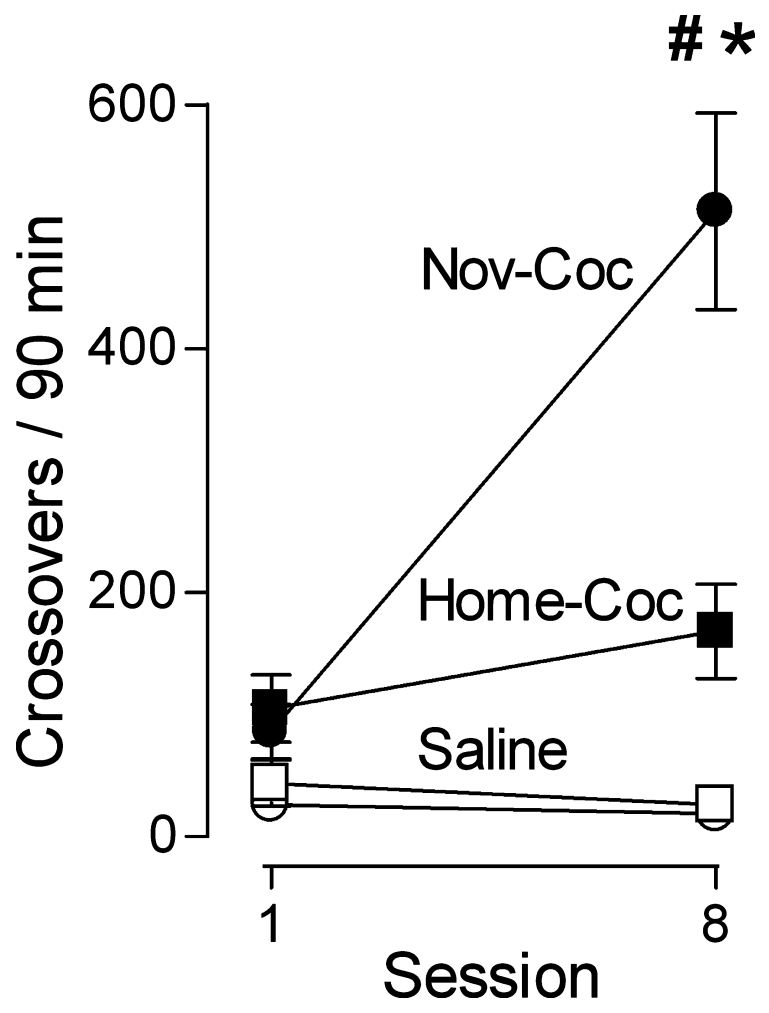

FIG. 1. The mean ( \pm SEM) number of crossovers (locomotor activity) during the 1st and 8th 90 min test sessions in animals given either $15 \mathrm{mg} / \mathrm{kg}$ of cocaine (ם) or saline $(\square)$ in their home cage, or $15 \mathrm{mg} / \mathrm{kg}$ of cocaine $(\mathbf{)})$ or saline $(\bigcirc)$ in a novel test cage. Activity during the $60 \mathrm{~min}$ habituation period is not shown. There was a significant increase in locomotor activity between the 1 st and 8th test session in animals given repeated injections of cocaine in the Novel condition (i.e. this group sensitized), but no change in animals given cocaine at Home (i.e. this group failed to sensitize). ${ }^{*}$ Differs from Day 1; \#Differs from the Home-Cocaine group.

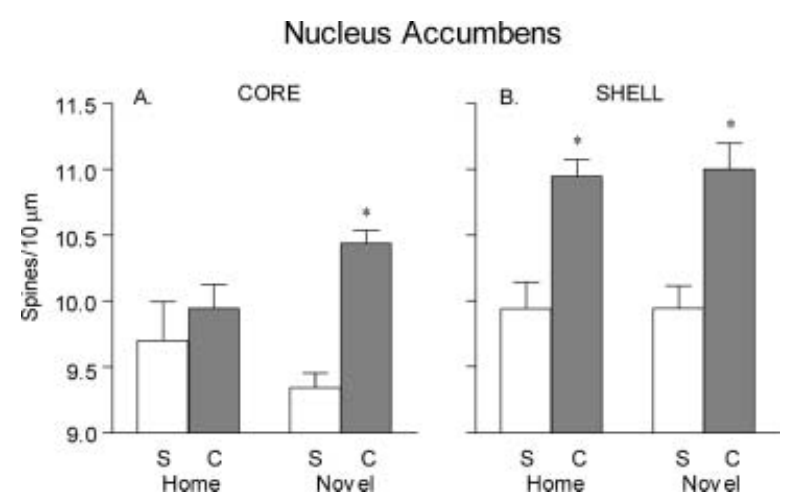

FIG. 2. The mean ( \pm SEM) number of dendritic spines per $10 \mu \mathrm{m}$ on medium spiny neurons in the core (A) of the nucleus accumbens (AcbC) and the shell (B) of the nucleus accumbens (AcbS), as a function of treatment condition. Repeated treatment with cocaine (C) in the Novel condition significantly increased spine density in the AcbC, relative to saline-treated animals (S). There was no effect of cocaine treatment in the AcbC in animals given cocaine at Home. Cocaine increased spine density in the AcbS to the same extent in animals-treated with cocaine at Home or in the Novel test cage.

effect of group (Home vs. Novel, $F=0.02, P=0.89$ ), a significant effect of drug (Saline vs. Cocaine, $F=31.7, P<0.0001$ ) but no group $\times$ drug interaction $(F=0.02, P=0.9)$. Thus, in the AcbS cocaine significantly increased spine density to the same extent in the Home and Novel groups. 


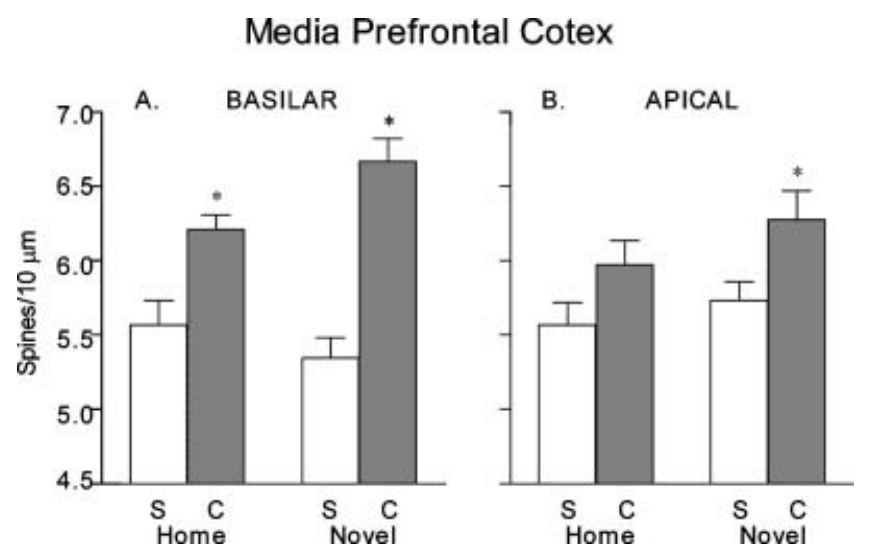

FIG. 3. The mean $( \pm$ SEM) number of dendritic spines per $10 \mu \mathrm{m}$ on the basilar (A) and apical (B) dendrites of layer $\mathrm{V}$ pyramidal cells in the medial prefrontal cortex, as a function of treatment condition. For basilar dendrites cocaine treatment increased spine density when given either at Home or in the Novel condition, but the effect in the Novel group was significantly greater than in the Home group. For apical dendrites the effect of cocaine treatment was significant only in the Novel group.

Medial prefrontal cortex. Figure 3 shows the effect of cocaine treatment on the density of dendritic spines on the basilar and apical dendrites of layer $\mathrm{V}$ pyramidal cells in the mPFC. For the basilar dendrites, a two-way ANOVA resulted in a significant group $\times$ drug interaction $(F=5.94, P=0.017)$. Post hoc Fisher's tests indicated that cocaine significantly increased spine density in the Novel group $(P<0.0001)$ and in the Home group $(P=0.002)$, but the significant interaction indicates that cocaine increased spine density to a significantly greater extent in the Novel group than in the Home group (and these two groups differed, $P=0.012$, Fisher's test). For the apical dendrites, a two-way ANOVA resulted in no significant effect of group (Home vs. Novel, $F=1.9, P=0.17$ ), a significant effect of drug (Saline vs. Cocaine, $F=7.6, P=0.008$ ) but no significant group $\times$ drug interaction $(F=0.16, P=0.69)$. However, post hoc Fisher's tests indicated that cocaine significantly increased spine density in the Novel group $(P=0.029)$ but the effect in the Home group was not statistically significant $(P=0.10)$.

Finally, we used the difference in the number of crossovers between day 8 of testing and day 1 of testing (day 8 minus day 1) as an index of the degree of sensitization in individual cocaine-treated animals, and averaged spine density values from the two hemispheres to obtain one value per rat, for the purposes of a correlational analysis (complete data were available from 11 animals/group). There was a significant positive correlation between the degree of psychomotor sensitization and spine density in the AcbC $(n=22, r=0.52, P=0.011)$, but no other correlations (AcbS, mPFC) were significant.

\section{Experiment 2}

Figure 4 shows the dose-response function for locomotor activity (crossovers) in the Home condition on the first and last (9th) test session. Animals received a single injection of $30 \mathrm{mg} / \mathrm{kg}$ (or saline) on the intervening days. There was a marked shift to the left in the dose-response function between the first and last test session, indicating that this higher dose of cocaine produced robust psychomotor sensitization, even though it was given at home $(F=5.81$, $P=0.005)$. Figure 5 shows that under these conditions, cocaine also produced a significant increase in the density of dendritic spines on

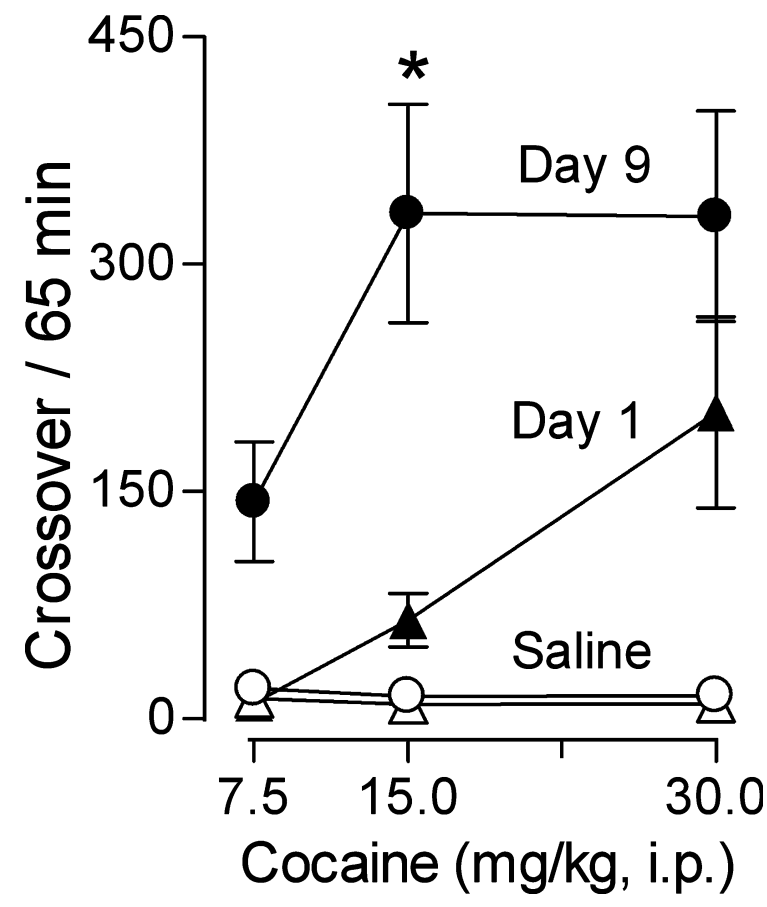

FIG. 4. The mean ( \pm SEM) number of crossovers during the 1st and last (9th) test session for animals treated in their home cage (experiment 2) with either saline (open symbols) or escalating doses of cocaine $(7.5,15$ and $30 \mathrm{mg} / \mathrm{kg}$; filled symbols). During the remaining daily test sessions (2-8) the cocainetreated group was given a single injection of $30 \mathrm{mg} / \mathrm{kg}$ of cocaine each day. Thus, sensitization is indicated here by a shift in the dose-response function between the 1 st and last test session. Note that under these conditions, cocaine produced robust behavioural sensitization, even though all drug treatments were given in the home cage.

\section{Nucleus Accumbens}

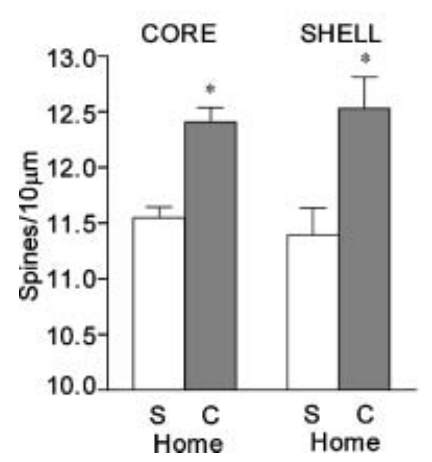

FIG. 5. The mean ( \pm SEM) number of dendritic spines per $10 \mu \mathrm{m}$ on medium spiny neurons in the core (left) of the nucleus accumbens (AcbC) and the shell (right) of the nucleus accumbens (AcbS), in animals-treated with either saline or cocaine $(30 \mathrm{mg} / \mathrm{kg})$ at Home (experiment 2). Note that under these conditions, cocaine treatment significantly increased spine density in both the $\mathrm{AcbC}$ and AcbS.

medium spiny neurons in both the AcbC (left, $t=2.88, P=0.009$ ) and the AcbS (right, $t=4.96, P<0.0001$ ).

\section{Discussion}

When rats were treated repeatedly with $15 \mathrm{mg} / \mathrm{kg}$ of cocaine in the Home condition there was no significant increase in psychomotor 
effect over time (i.e. this dose failed to induce sensitization), but when the same dose was given in the Novel condition it induced robust psychomotor sensitization. These data are consistent with our previous studies using this environmental manipulation (Badiani et al., 1995; Browman et al., 1998a), and indicate that in Experiment 1 we achieved our goal of holding drug history constant while varying the ability of cocaine to induce psychomotor sensitization. We were able to ask therefore whether structural plasticity was produced by mere exposure to cocaine, or whether structural plasticity was associated with the ability of cocaine to induce psychomotor sensitization. The answer to this question differed depending on the brain region studied. Cocaine altered synaptic organization in some brain regions (AcbS and $\mathrm{mPFC}$ ) whether it was given in a Novel environment or at Home, and therefore, independent of whether drug treatment induced psychomotor sensitization. However, only when cocaine was given under the condition that promoted psychomotor sensitization did it change synaptic organization AcbC, and its effect in the mPFC was of greater magnitude.

The environmental manipulation used here does not gate sensitization in an all-or-none fashion, but as dose is increased robust sensitization is seen even when drugs are given at Home. Environmental context merely shifts the dose-response function for inducing psychomotor sensitization (Browman et al., 1998a,b). We predicted therefore that if the dose of cocaine were increased such that it now induced behavioural sensitization, even when given at Home, and if structural plasticity in the AcbC is related to the ability of cocaine to induce sensitization, then under these conditions cocaine should come to increase spine density in the AcbC. We confirmed this prediction in experiment 2. Repeated injections of $30 \mathrm{mg} / \mathrm{kg}$ of cocaine at Home (vs. $15 \mathrm{mg} / \mathrm{kg}$ in experiment 1) produced robust behavioural sensitization, and increased spine density in both the AcbC and AcbS.

There are previous studies suggesting that psychomotor sensitization preferentially involves alterations in AcbC-related circuitry. For example, Cadoni, Di Chiara and colleagues (Cadoni \& Di Chiara, 1999, 2000; Cadoni et al., 2000) have reported that sensitization to morphine, nicotine, cocaine and amphetamine is associated with increased dopamine (DA) release in the AcbC (but not AcbS, where in fact DA is sometimes decreased). Recently Hédou et al., 2002) reported that amphetamine sensitization is accompanied by increased Fos expression in the AcbC (and not AcbS). Lastly, the AcbC (and not AcbS) projects both directly and indirectly to the subthalamic nucleus (STN) (Zahm, 2000), and locomotor sensitization is associated with increased c-fos mRNA expression in the STN (Uslaner et al., 2003a). However, this literature is not consistent and for every example of a neural correlate of sensitization in the AcbC one can find examples of a change in the AcbS (e.g. Pierce \& Kalivas, 1995; Todtenkopf et al., 2002). Indeed, even a cursory review of the literature on the neurobiology of sensitization reveals that many so-called neural correlates of sensitization have been reported in many brain regions. Repeated treatment with psychomotor stimulant drugs, using protocols that induce behavioural sensitization, has been reported to alter nearly every neurotransmitter system in the Acb, including DA, norepinephrine, 5-HT, acetylcholine, glutamate, GABA, endogenous opioid transmitters, etc., and a host of intracellular signalling molecules, growth factors, transcription factors, etc., and many of these changes have been found in the AcbS as well as the AcbC (Stewart \& Badiani, 1993; Pierce \& Kalivas, 1997; White \& Kalivas, 1998; Wolf, 1998; Robinson \& Berridge, 2000; Vanderschuren \& Kalivas, 2000; Kalivas, 2004). However, it is possible that many of these drug-induced changes in the brain are not actually related to whether the drug treatments produced sensitization, but occur as a consequence of mere drug history, and this may account for some of the apparent inconsistencies in the literature.

To our knowledge, in the entire literature on neurobiological correlates of sensitization, there has never been an attempt to dissociate the effects of mere drug history from the ability of drugs to induce sensitization (with one exception - see below). That is, in studies that have reported neurobiological correlates of sensitization (including our own, e.g. Robinson et al., 1988) typically a drug is given repeatedly, and this induces both sensitization and a change in some brain measure. However, this procedure does not allow one to determine whether it was necessary for the drug treatment to induce sensitization to produce a given change in brain, or whether drug exposure itself was sufficient, because the effects of mere drug history are confounded with the effects of drug-induced sensitization (although there have been attempts to see if treatments that prevent sensitization also block a given neural correlate of sensitization; e.g. Wolf et al., 1994). The results reported here clearly establish that mere exposure to cocaine, in the absence of measurable psychomotor sensitization, can produce structural plasticity in the AcbS. In contrast, structural plasticity was seen in the AcbC only if cocaine treatment also produced sensitization. Given that neuroadaptations responsible for sensitization may contribute to the transition from casual or experimental drug use to the compulsive patterns of drug pursuit that characterize addiction (Robinson \& Berridge, 1993; Vanderschuren \& Kalivas, 2000; Robinson \& Berridge, 2003; Vezina, 2004), it will be important to know which drug-induced changes in brain are related to sensitization, and which are not. Procedures such as those described here may be valuable in this regard.

We are aware of only one previous study that attempted to dissociate drug history from sensitization. Pierce et al. (1996) explicitly divided cocaine-treated animals into those that sensitized vs. those that did not and then examined effects on the AcbC vs. AcbS. Interestingly, Pierce et al. (1996) found that a cocaine challenge increased extracellular glutamate in the AcbC (not AcbS) in animals sensitized to cocaine, but not in cocaine-treated rats that failed to develop sensitization. However, one short-coming of this approach as a method to dissociate drug history from drug-induced sensitization is that it is impossible to tell whether group differences in the brain are due to differential drug treatment effects (neural plasticity), or whether the two groups differed prior to any drug treatment. Indeed, in the Pierce et al. study (1996), the behavioural response to the first injection of cocaine was different in the subset of animals that sensitized than in the subset that did not sensitize (see their table 1), suggesting pre-existing differences. If differences in the brain in these selected subgroups reflect two different phenotypes from different portions of a normally distributed population, this would be akin to comparing so-called high responder and low responder subgroups, which also sensitize differentially, but are known to have very different brains even before they are ever exposed to drug (Piazza et al., 1998). This problem is avoided in the present study because animals in the population are assigned randomly to two groups; they are not selected based on some phenotype.

Nevertheless, it is interesting that Pierce et al. (1996) found that sensitization increased glutamate release in the AcbC and not AcbS, because glutamate synapses are found on the heads of dendritic spines, and in the Acb and mPFC spines are thought to be the locus of DA/glutamate interactions (Sesack \& Pickel, 1990; Smith \& Bolam, 1990; Groenewegen et al., 1991; Goldman-Rakic et al., 1992). Furthermore, we have found that amphetamine preferentially increases spine density on the distal portion of the dendritic tree of medium spiny neurons ( $\mathrm{Li}$ et al., 2003), which is the location of DA and glutamate synapses on these cells. Therefore, to the extent that the 
changes in spine density reported here reflect changes in the number of synapses, which is the case for many other forms of experiencedependent plasticity (Greenough et al., 1990; Kolb et al., 1998; Woolley, 1998), our data suggest that sensitization-related changes in patterns of synaptic connectivity specifically in the AcbC (and mPFC) may represent the structural basis of changes in DA/glutamate signalling that has been associated with sensitization.

Of course, we are assuming that the structural changes in dendritic spines described here reflect changes in synapses, changes that alter the operation of the relevant circuits. It is important to acknowledge therefore that it is impossible to tell how (or if) dendritic reorganization characterized at this level of structural analysis alters the operation of cells or circuits. Indeed, very different changes in structure, such as an increase vs. a decrease in spine density on a given dendritic segment of a cell, could have exactly the same outcome in terms of how cell signalling and the operation of the circuit is altered depending on how different synaptic inputs are rearranged around the altered postsynaptic surface. By the same token, apparently similar alterations in dendrites produced by different treatments could have very different outcomes for the operation of cells and circuits, if synaptic inputs are rearranged differently. To determine how the kind of synaptic reorganization described here alters the operation of cells and circuits will require both ultra-structural and electrophysiological approaches. We also do not know the neurobiological mechanisms by which environmental context modulates drug-induced plasticity. However, environmental context does modulate the ability of psychostimulant drugs to induce immediate early genes in many brain regions (Badiani et al., 1998, 1999; Day et al., 2001; Uslaner et al., 2003a,b), and this could be related to the effect of context on synaptic plasticity reported here.

Given that this is the first report of a drug-induced change in the brain that has been specifically linked to whether drug administration produced sensitization or not, and given that sensitization was associated specifically with structural plasticity in the AcbC (but not AcbS), it behoves us to briefly consider what behavioural/psychological functions are mediated by the AcbC vs. the AcbS (Cardinal et al., 2002). There is increasing evidence that the AcbC is especially important in mediating the motivational impact of Pavlovian conditioned stimuli (CSs) on behaviour, as assessed by: (i) Pavlovian conditioned approach - that is, the tendency to approach CSs; (ii) conditioned reinforcement (CRf) - the process by which a Pavlovian $\mathrm{CS}$ reinforces instrumental responses and (iii) Pavlovian-instrumental transfer (PIT) - the process by which noncontingent presentation of a CS facilitates ongoing instrumental actions. Everitt, Robbins and their colleagues (for reviews, see Everitt et al., 2000; Cardinal et al., 2002) have found that the AcbC (but not AcbS) is critical for both Pavlovian conditioned approach (Parkinson et al., 1999; Di Ciano et al., 2001) and PIT (Hall et al., 2001; de Borchgrave et al., 2002; compare Corbit et al., 2001), and the noncontingent presentation of a Pavlovian CS increases extracellular DA in the AcbC, but not AcbS (Ito et al., 2000). This may be related to reports that AcbC-related circuitry is critical for the reinstatement of drug-seeking behaviour following extinction of self-administration (e.g. McFarland \& Kalivas, 2001; for review, see Kalivas \& McFarland, 2003). Lesions of both the AcbC and AcbS impair aspects of CRf, but in different ways - the AcbS appears to be especially important in mediating the potentiating effects of psychostimulant drugs on CRf (Parkinson et al., 1999), but the AcbC appears to be especially important for the ability of conditioned reinforcers to maintain instrumental actions (Ito et al., 2004). The AcbS also appears to be especially important in mediating the impact of primary reinforcers, including food and drugs, as well as aversive stimuli (Cardinal et al., 2002).
It is especially relevant that all of these aspects of Pavlovian conditioned motivation have been reported to be enhanced by past drug treatment (i.e. they appear to sensitize). Prior exposure to psychostimulant drugs facilitates Pavlovian conditioned approach (Harmer \& Phillips, 1998, 1999; Taylor \& Jentsch, 2001), PIT (Wyvell $\&$ Berridge, 2001) and the potentiative effects of psychostimulants on CRf (Taylor \& Horger, 1999; Mead et al., 2004). Indeed, the facilitatory effects of past drug treatment on the acquisition of drug self-administration behaviour (Piazza et al., 1989; Horger et al., 1990), conditioned place preference (Lett, 1989) and progressive ratio responding (Mendrek et al., 1998; Lorrain et al., 2000) could all be secondary to sensitization of Pavlovian motivational processes, that is, to sensitization of incentive salience (Robinson \& Berridge, 2000, 2003). Thus, drug-induced synaptic reorganization in the AcbC may be especially important for both psychomotor sensitization and for incentive sensitization (assuming that both forms of sensitization are sensitive to the environmental manipulation used here).

In closing, the extent to which the effects of past drug history on subsequent behaviour and psychological function are due to neuroadaptations that accompany the development of any form of sensitization, vs. those that occur independent of sensitization, is almost completely unexplored. This is an interesting question given that the development of psychomotor sensitization has been related directly to increases in drug motivated behaviour (De Vries et al., 1998, 2002). Thus, if forms of synaptic plasticity responsible directly for sensitization play an especially important role in the process by which repeated drug use leads to addiction, the data reported here suggest that synaptic reorganization in specifically the AcbC (and mPFC) may be critically involved in the transition to addiction.

\section{Acknowledgements}

This research was supported by a grant to T.E.R. from the National Institute on Drug Abuse (R01 DA013398). T.E.R. was also supported by a NIDA Senior Scientist Award (K05 DA00473). We thank Kent Berridge, Barry Everitt, Carrie Ferrario, Bryan Kolb and Jane Stewart for helpful comments on an earlier draft.

\section{Abbreviations}

Acb, nucleus accumbens; AcbC, Acb core; AcbS, Acb shell; DA, dopamine; $\mathrm{mPFC}$, medial prefrontal cortex; STN, subthalamic nucleus.

\section{References}

Badiani, A., Browman, K.E. \& Robinson, T.E. (1995) Influence of novel versus home environments on sensitization to the psychomotor stimulant effects of cocaine and amphetamine. Brain Res., 674, 291-298.

Badiani, A., Oates, M.M., Day, H.E.W., Watson, S.J., Akil, H. \& Robinson, T.E. (1998) Amphetamine-induced behavior, dopamine release, and c-fos mRNA expression: modulation by environmental novelty. J. Neurosci., 18, 10579-10593.

Badiani, A., Oates, M.M., Day, H.E.W., Watson, S.J., Akil, H. \& Robinson, T.E. (1999) Environmental modulation of amphetamine-induced c-fos expression in D1 versus D2 striatal neurons. Behav. Brain Res., 103, 203209.

de Borchgrave, R., Rawlins, J.N., Dickinson, A. \& Balleine, B.W. (2002) Effects of cytotoxic nucleus accumbens lesions on instrumental conditioning in rats. Exp. Brain Res., 144, 50-68.

Browman, K.E., Badiani, A. \& Robinson, T.E. (1998a) The influence of environment on the induction of sensitization to the psychomotor activating effects of intravenous cocaine in rats is dose-dependent. Psychopharmacology, 137, 90-98.

Browman, K.E., Badiani, A. \& Robinson, T.E. (1998b) Modulatory effect of environmental stimuli on the susceptibility to amphetamine sensitization: a dose-effect study in rats. J. Pharmacol. Exp. Ther., 287, 1007-1014. 
Cadoni, C. \& Di Chiara, G. (1999) Reciprocal changes in dopamine responsiveness in the nucleus accumbens shell and core and in the dorsal caudate-putamen in rats sensitized to morphine. Neuroscience, 90, 447455.

Cadoni, C. \& Di Chiara, G. (2000) Differential changes in accumbens shell and core dopamine in behavioral sensitization to nicotine. Eur. J. Pharmacol., 387, R23-R25.

Cadoni, C., Solinas, M. \& Di Chiara, G. (2000) Psychostimulant sensitization: differential changes in accumbal shell and core dopamine. Eur. J. Pharmacol., 388, 69-76.

Cardinal, R.N., Parkinson, J.A., Hall, J. \& Everitt, B.J. (2002) Emotion and motivation: the role of the amygdala, ventral striatum, and prefrontal cortex. Neurosci. Biobehav Rev., 26, 321-352.

Corbit, L.H., Muir, J.L. \& Balleine, B.W. (2001) The role of the nucleus accumbens in instrumental conditioning: Evidence of a functional dissociation between accumbens core and shell. J. Neurosci., 21, 32513260 .

Crombag, H.S., Badiani, A. \& Robinson, T.E. (1996) Signalled versus unsignalled intravenous amphetamine: large differences in the acute psychomotor response and sensitization. Brain Res., 722, 227-231.

Day, H.E.W., Badiani, A., Uslaner, J., Oates, M.M., Vittoz, N.M., Robinson, T.E., Watson, S.J. \& Akil, H. (2001) Environmental novelty differentially affects amphetamine-induced c-fos mRNA expression in subregions of the bed nucleus of the stria terminalis and amygdala. J. Neurosci., 21, 732-740.

De Vries, T.J., Schoffelmeer, A.N., Binnekade, R., Mulder, A.H. \& Vanderschuren, L.J. (1998) Drug-induced reinstatement of heroin- and cocaine-seeking behaviour following long-term extinction is associated with expression of behavioural sensitization. Eur. J. Neurosci., 10, 3565-3571.

De Vries, T.J., Schoffelmeer, A.N., Binnekade, R., Raaso, H. \& Vanderschuren, L.J. (2002) Relapse to cocaine- and heroin-seeking behavior mediated by dopamine D2 receptors is time-dependent and associated with behavioral sensitization. Neuropsychopharmacology, 26, 18-26.

Di Ciano, P., Cardinal, R.N., Cowell, R.A., Little, S.J. \& Everitt, B.J. (2001) Differential involvement of NMDA, AMPA/kainate, and dopamine receptors in the nucleus accumbens core in the acquisition and performance of pavlovian approach behavior. J. Neurosci., 21, 9471-9477.

Everitt, B.L., Cardinal, R.N., Hall, J., Parkinson, J.A. \& Robbins, T.W. (2000) Differential involvement of amygdala subsystems in appetitive conditioning and drug addiction. In Aggleton, J.P., (ed.) The Amygdala: a Functional Analysis. Oxford University Press, New York, pp. 353-390.

Gibb, R. \& Kolb, B. (1998) A method for vibratome sectioning of Golgi-Cox stained whole rat brain. J. Neurosci. Meth., 79, 1-4.

Goldman-Rakic, P.S., Lidow, M.S., Smiley, J.F. \& Williams, M.S. (1992) The anatomy of dopamine in monkey and human prefrontal cortex. J. Neural Transm., 36, 163-177.

Greenough, W.T., Withers, G.S. \& Wallace, C.S. (1990) Morphological changes in the nervous system arising from behavioral experience: what is the evidence that they are involved in learning and memory?. In Squire, L.R. \& Lindenlaub, E. (eds), The Biology of Memory, Symposia Medica Hoechst. F. K. Schattauder Verlag, New York, pp. 159-185.

Groenewegen, H.J., Berendse, H.W., Meredith, G.E., Haber, S.N., Voorn, P., Wolters, J.G. \& Lohman, A.H.M. (1991) Functional anatomy of the ventral, limbic system-innervated striatum. In Willner, P. \& Scheel-Krüger, J. (eds), The Mesolimbic Dopamine System: from Motivation to Action. John Wiley \& Sons, New York, pp. 19-59.

Hall, J., Parkinson, J.A., Connor, T.M., Dickinson, A. \& Everitt, B.J. (2001) Involvement of the central nucleus of the amygdala and nucleus accumbens core in mediating Pavlovian influences on instrumental behaviour. Eur. J. Neurosci., 13, 1984-1992.

Harmer, C.J. \& Phillips, G.D. (1998) Enhanced appetitive conditioning following repeated pretreatment with d- amphetamine. Behav. Pharmacol., 9, 299-308.

Harmer, C.J. \& Phillips, G.D. (1999) Enhanced dopamine efflux in the amygdala by a predictive, but not a non- predictive, stimulus: facilitation by prior repeated D-amphetamine. Neuroscience, 90, 119-130.

Hédou, G., Jongen-Relo, A.L., Murphy, C.A., Heidbreder, C.A. \& Feldon, J. (2002) Sensitized Fos expression in subterritories of the rat medial prefrontal cortex and nucleus accumbens following amphetamine sensitization as revealed by stereology. Brain Res., 950, 165-179.

Horger, B.A., Shelton, K. \& Schenk, S. (1990) Preexposure sensitizes rats to the rewarding effects of cocaine. Pharm. Biochem. Behav, 37, 707-711.

Ito, R., Dalley, J.W., Howes, S.R., Robbins, T.W. \& Everitt, B.J. (2000) Dissociation in conditioned dopamine release in the nucleus accumbens core and shell in response to cocaine cues and during cocaine-seeking behavior in rats. J. Neurosci., 20, 7489-7495.
Ito, R., Robbins, T.W. \& Everitt, B.J. (2004) Differential control over cocaineseeking behavior by nucleus accumbens core and shell. Nature Neurosci., 7, 389-397.

Kalivas, P.W. (2004) Glutamate systems in cocaine addiction. Curr. Opin. Pharmacol., 4, 23-29.

Kalivas, P.W. \& McFarland, K. (2003) Brain circuitry and the reinstatement of cocaine-seeking behavior. Psychopharmacology (Berlin), 168, 44-56.

Kolb, B., Forgie, M., Gibb, R., Gorny, G. \& Rowntree, S. (1998) Age, experience and the changing brain. Neurosci. Biobehav. Rev., 22, 143-159.

Lett., B.T. (1989) Repeated exposures intensify rather than diminish the rewarding effects of amphetamine, morphine, and cocaine. Psychopharmacology (Berlin), 98, 357-362.

Li, Y., Kolb, B. \& Robinson, T.E. (2003) The location of persistent amphetamine-induced changes in the density of dendritic spines on medium spiny neurons in the nucleus accumbens and caudate-putamen. Neuropsychopharmacology, 238, 1082-1085.

Lorrain, D.S., Arnold, G.M. \& Vezina, P. (2000) Previous exposure to amphetamine increases incentive to obtain the drug: long-lasting effects revealed by the progressive ratio schedule. Behav. Brain Res., 107, 9-19.

McFarland, K. \& Kalivas, P.W. (2001) The circuitry mediating cocaine-induced reinstatement of drug-seeking behavior. J. Neurosci., 21, 8655-8663.

Mead, A.N., Crombag, H.S. \& Rocha, B.A. (2004) Sensitization of psychomotor stimulation and conditioned reward in mice: differential modulation by contextual learning. Neuropsychopharmacology, 29, 249258.

Mendrek, A., Blaha, C.D. \& Phillips, A.G. (1998) Pre-exposure of rats to amphetamine sensitizes self-administration of this drug under a progressive ratio schedule. Psychopharmacology, 135, 416-422.

Parkinson, J.A., Olmstead, M.C., Burns, L.H., Robbins, T.W. \& Everitt, B.J. (1999) Dissociation in effects of lesions of the nucleus accumbens core and shell on appetitive pavlovian approach behavior and the potentiation of conditioned reinforcement and locomotor activity by D-amphetamine. J. Neurosci., 19, 2401-2411.

Piazza, P.V., Deminière, J.M., Le Moal, M. \& Simon, H. (1989) Factors that predict individual vulnerability to amphetamine self-administration. Science, 245, 1511-1513.

Piazza, P.V., Deroche, V., Rouge-Pont, F. \& Le Moal, M. (1998) Behavioral and biological factors associated with individual vulnerability to psychostimulant abuse. NIDA Res. Monogr., 169, 105-133.

Pierce, R.C., Bell, K., Duffy, P. \& Kalivas, P.W. (1996) Repeated cocaine augments excitatory amino acid transmission in the nucleus accumbens only in rats having developed behavioral sensitization. J. Neurosci., 16, 1550-1560.

Pierce, R.C. \& Kalivas, P.W. (1995) Amphetamine produces sensitized increases in locomotion and extracellular dopamine preferentially in the nucleus accumbens shell of rats administered repeated cocaine. J. Pharmacol. Exp. Ther, 275, 1019-1029.

Pierce, R.C. \& Kalivas, P.W. (1997) A circuitry model of the expression of behavioral sensitization to amphetamine-like psychostimulants. Brain Res. Rev., 25, 192-216.

Pierre, P.J. \& Vezina, P. (1998) D1 dopamine receptor blockade prevents the facilitation of amphetamine self-administration induced by prior exposure to the drug. Psychopharmacology (Berlin), 138, 159-166.

Robinson, T.E. \& Becker, J.B. (1986) Enduring changes in brain and behavior produced by chronic amphetamine administration: a review and evaluation of animal models of amphetamine psychosis. Brain Res. Rev., 11, 157-198.

Robinson, T.E. \& Berridge, K.C. (1993) The neural basis of drug craving: an incentive-sensitization theory of addiction. Brain Res. Rev., 18, 247-291.

Robinson, T.E. \& Berridge, K.C. (2000) The psychology and neurobiology of addiction: an incentive-sensitization view. Addiction, 95, S91-S117.

Robinson, T.E. \& Berridge, K.C. (2003) Addiction. Annu. Rev. Psychol, 54, $25-53$.

Robinson, T.E., Gorny, G., Mitton, E. \& Kolb, B. (2001) Cocaine selfadministration alters the morphology of dendrites and dendritic spines in the nucleus accumbens and neocortex. Synapse, 39, 257-266.

Robinson, T.E., Jurson, P.A., Bennett, J.A. \& Bentgen, K.M. (1988) Persistent sensitization of dopamine neurotransmission in ventral striatum (nucleus accumbens) produced by past experience with (+)-amphetamine: a microdialysis study in freely moving rats. Brain Res., 462, 211-222.

Robinson, T.E. \& Kolb, B. (1997) Persistent structural modifications in nucleus accumbens and prefrontal cortex neurons produced by previous experience with amphetamine. J. Neurosci., 17, 8491-8497.

Robinson, T.E. \& Kolb, B. (1999) Alterations in the morphology of dendrites and dendritic spines in the nucleus accumbens and prefrontal cortex following repeated treatment with amphetamine or cocaine. Eur. J. Neurosci., 11, 1598-1604. 
Segal, D.S. \& Mandell, A.J. (1974) Long-term administration of Damphetamine: progressive augmentation of motor activity and stereotypy. Pharmacol. Biochem. Behav., 2, 249-255.

Sesack, S.R. \& Pickel, V.M. (1990) In the rat medial nucleus accumbens, hippocampal and catecholaminergic terminals converge on spiny neurons and are in apposition to each other. Brain Res., 527, 266-279.

Smith, A.D. \& Bolam, J.P. (1990) The neural network of the basal ganglia as revealed by the study of synaptic connections of identified neurons. Trends Neurosci., 13, 259-265.

Stewart, J. \& Badiani, A. (1993) Tolerance and sensitization to the behavioral effects of drugs. Behav. Pharmacol., 4, 289-312.

Taylor, J.R. \& Horger, B.A. (1999) Enhanced responding for conditioned reward produced by intra-accumbens amphetamine is potentiated after cocaine sensitization. Psychopharmacology, 142, 31-40.

Taylor, J.R. \& Jentsch, J.D. (2001) Repeated intermittent administration of psychomotor stimulant drugs alters the acquisition of Pavlovian approach behavior in rats: differential effects of cocaine, D-amphetamine and 3,4methylenedioxymethamphetamine ('Ecstasy'). Biol. Psychiatry, 50, 137143.

Todtenkopf, M.S., Mihalakopoulos, A. \& Stellar, J.R. (2002) Withdrawal duration differentially affects c-fos expression in the medial prefrontal cortex and discrete subregions of the nucleus accumbens in cocaine-sensitized rats. Neuroscience, 114, 1061-1069.

Uslaner, J.M., Crombag, H.S., Ferguson, S.M. \& Robinson, T.E. (2003a) Cocaine-induced psychomotor activity is associated with its ability to induce c-fos mRNA expression in the subthalamic nucleus: effects of dose and repeated treatment. Eur. J. Neurosci., 17, 2180-2186.
Uslaner, J.M., Norton, C.S., Watson, S.J., Akil, H. \& Robinson, T.E. (2003b) Amphetamine-induced c-fos mRNA expression in the caudate-putamen and subthalamic nucleus: interactions between dose, environment, and neuronal phenotype. J. Neurochem., 85, 105-114.

Vanderschuren, L.J. \& Kalivas, P.W. (2000) Alterations in dopaminergic and glutamatergic transmission in the induction and expression of behavioral sensitization: a critical review of preclinical studies. Psychopharmacology, 151, 99-120.

Vezina, P. (2004) Sensitization of midbrain dopamine neuron reactivity and the self-administration of psychomotor stimulant drugs. Neurosci. Biobehav. Rev., 27, 827-839.

White, F.J. \& Kalivas, P.W. (1998) Neuroadaptations involved in amphetamine and cocaine addiction. Drug Alcohol Depend., 51, 141-153.

Wolf, M.E. (1998) The role of excitatory amino acids in behavioral sensitization to psychomotor stimulants. Prog. Neurobiol., 54, 679-720.

Wolf, M.E., White, F.J. \& Hu, X.T. (1994) MK-801 prevents alterations in the mesoaccumbens dopamine system associated with behavioral sensitization to amphetamine. J. Neurosci., 14, 1735-1745.

Woolley, C.S. (1998) Estrogen-mediated structural and functional synaptic plasticity in the female rat hippocampus. Horm. Behav., 34, $140-148$.

Wyvell, C.L. \& Berridge, K.C. (2001) Incentive sensitization by previous amphetamine exposure: increased cue- triggered 'wanting' for sucrose reward. J. Neurosci., 21, 7831-7840.

Zahm, D.S. (2000) An integrative neuroanatomical perspective on some subcortical substrates of adaptive responding with emphasis on the nucleus accumbens. Neurosci. Biobehav. Rev., 24, 85-105. 